\title{
Artigos
}

\section{O distanciamento social em tempos de Covid-19: uma análise de seus rebatimentos em torno da violência doméstica}

\author{
Social distancing in times of Covid-19: an analysis of its effects on domestic \\ violence (abstract: p. 19)
}
El distanciamiento social en tiempos de Covid-19: un análisis de sus implicaciones alrededor de la violencia doméstica (resumen: p. 19)

Emanuella de Castro Marcolino(a)
<emanuella.de.castro@gmail.com> (D)

Renata Clemente dos Santos ${ }^{(b)}$

$<$ renata.clemente@hotmail.com>

Francisco de Sales Clementino ${ }^{(\mathrm{c})}$

<fclementino67@yahoo.com.br> (iD

Cláudia Quézia Amado Monteiro Leal ${ }^{(\mathrm{d})}$

<claudiaquezia@hotmail.com>

Maria Cidney da Silva Soares ${ }^{(e)}$

<profcidneysoares@hotmail.com>

continua pág. 15

\author{
(a,b,d,e) Centro Universitário \\ (UNIFACISA). Av. Sen. Argemiro \\ de Figueiredo, 1901, Itararé, \\ Campina Grande, Paraíba (PB), \\ Brasil. 58411-020. \\ (c) Universidade Federal de \\ Campina Grande. Campina \\ Grande, PB, Brasil. \\ (f) Universidade Federal do Rio \\ Grande do Norte. Natal, Rio \\ Grande do Norte, Brasil. \\ (a) Universidade Federal da Paraíba. \\ João Pessoa, PB, Brasil.
}

O objetivo do presente artigo foi analisar os rebatimentos do distanciamento social em tempos de Covid-19 em torno da violência doméstica. Trata-se de um estudo documental com abordagem qualitativa feito por meio do conteúdo de notícias disponíveis em quatro jornais on-line de circulação nacional. Foram incluídas notícias publicadas entre 20 de março e 25 de abril de 2020 com as temáticas distanciamento social e violência doméstica, analisadas pelo software Interface de R pourles Analyses Multidimensionnelles de Textes et de Questionnaires (Iramuteq) associado à análise de conteúdo de Bardin. A análise lexicográfica e de conteúdo do corpus textual de 102 notícias produziu quatro categorias temáticas com foco na rede de proteção, ambiente doméstico, elevação dos casos de violência doméstica e contexto de pandemia como potencializador do fenômeno. 0 distanciamento social decorrente da pandemia de Covid-19 potencializou as situações de violência doméstica, demonstrando necessidade de medidas de intervenção e fortalecimento da rede de proteção.

Palavras-chave: Violência doméstica. Violência. Coronavírus. Pandemia. Distanciamento social.

Marcolino EC, Santos RC, Clementino FS, Leal CQAM, Soares MCS, Miranda FAN, Souto RQ. O distanciamento social em tempos de Covid-19: uma análise de seus rebatimentos em torno da violência doméstica. Interface (Botucatu). 2021; 25(Supl. 1): e200363 https://doi.org/10.1590/Interface.200363 


\section{Introdução}

A violência é um fenômeno legitimado pela própria sociedade e possui raízes nas desigualdades sociais e iniquidades visíveis. Por isso, é uma problemática de caráter social e transformou-se em um problema mundial de saúde pública com consequências como mortes e adoecimentos, cada vez mais presentes em ambientes sociais como escolas e ambientes domésticos ${ }^{1,2}$.

Conceitualmente, a Organização Mundial de Saúde (OMS) categorizou a violência segundo quem a comete. As categorias são: autoinfligida (ideação suicida, tentativa de suicídio, o próprio suicídio ou automutilação), interpessoal (violência doméstica, entre parceiro íntimo ou comunitária) e violência coletiva (social, política e econômica) ${ }^{3}$. A violência doméstica (VD) surge como questão social importante, sendo mais conhecida por referência aos abusos e maus-tratos sofridos pelas crianças, mulheres e idosos ${ }^{4}$.

A VD é uma das mais importantes causas de instabilidade familiar, ocasionando impacto na morbimortalidade de seus componentes nas diferentes camadas sociais. Envolve aspectos socioculturais, psicológicos, comportamentais e econômicos; prejudica a saúde; viola os direitos humanos; e muitas vezes é acompanhada pelo silêncio e submissão das vítimas na esfera do espaço microssocial dos domicílios ${ }^{5,6}$.

O panorama atual de pandemia pelo novo coronavírus despertou preocupação mundial, uma vez que desencadeia ou potencializa desajustes sociais, afetivos e psicológicos na população pela susceptibilidade a sentimentos de insegurança, impotência, quadros de ansiedade, depressão e até tentativas de suicídio ${ }^{7-9}$. As normas e regras de distanciamento social adotadas como medida em busca de minimizar a transmissão do vírus trouxe modificaçôes decisivas no cotidiano da população mundial ${ }^{10}$.

Contudo, apesar dos benefícios impostos em função da contenção da doença, o distanciamento social pode aumentar a vulnerabilidade de mulheres, crianças, adolescentes e idosos a situaçôes de violência doméstica, uma vez que as vítimas permanecem mais tempo no ambiente doméstico e, portanto, mais tempo em contato com os perpetradores da situação violenta, além de haver a diminuição significativa da rede de apoio que viabiliza diálogos com familiares e amigos, ampliando assim a exposição para vivência do ciclo de violência ${ }^{11}$.

O cenário internacional e nacional demonstra a magnitude da violência doméstica em tempos de pandemia. Já se identifica um aumento significativo de casos de violência doméstica em países em situações de confinamento obrigatório, como China, Espanha, Itália e Brasil, sendo que este último se destaca, com uma estimativa de aumento de $50 \%$ de denúncias comparada ao período anterior ao confinamento social, conforme dados do Ministério Público do Estado do Rio de Janeiro ${ }^{12}$. Adicionalmente, o perfil sociodemográfico de vítimas de violência doméstica encontra-se associado a características de vulnerabilidade, evidenciado pela dependência financeira da vítima e pelo distanciamento de vínculos com membros de sua rede social de apoio ${ }^{13}$.

Diante dos impactos decorrentes das medidas para contenção da Covid-19, como instabilidades econômicas e sociais, incluindo a elevação de casos de violência doméstica e influência direta a grupos vulneráveis que já sofrem violaçóes de direitos em seus cotidianos ${ }^{11}$, questiona-se: quais os rebatimentos 
do distanciamento social em tempos de Covid-19 no que concerne à violência doméstica? Este estudo objetivou analisar os rebatimentos do distanciamento social em tempos de Covid-19 em torno da violência doméstica.

\section{Método}

Trata-se de uma pesquisa documental, interpretativa, retrospectiva e com abordagem qualitativa desenvolvida com notícias disponíveis em quatro jornais de grande circulação no Brasil, a saber: "Estadão", "Gazeta do Povo", "G1" e "UR7".

Os jornais foram selecionados pelos critérios de atualização diária, alcance em todo território brasileiro com notícias das cinco regiões do país, amplo acesso e visitação nacional. A amostra foi composta por notícias publicadas de 20 de março de 2020 a 25 de abril de 2020. A definição da data pautou-se no Boletim Epidemiológico $07^{14}$ especial para a Covid-19 produzido pelo Centro de Operaçóes de Emergência em Saúde Pública do Ministério da Saúde, que estabeleceu o dia 20 de março de $2020^{14}$ como o início do processo de mitigação no território brasileiro com consequente distanciamento social. $\mathrm{O}$ acesso às notícias foi dado mediante clipagem e assinatura temporária dos jornais.

As notícias foram mediadas pelo uso dos termos-chaves "violência doméstica", "abuso", "abuso doméstico", "violência na família” e "maus-tratos”, aplicados separadamente na ferramenta de busca de cada homepage e incluídos mediante os seguintes critérios: publicação após 20 de março de 2020 e notícias relacionadas ao Brasil que abordassem a violência doméstica e o distanciamento social em decorrência da pandemia de Covid-19.

A captura dos dados ocorreu entre 26 de abril e 3 de maio de 2020. Foi elaborado inicialmente um protocolo norteador de busca contendo um quadro com as variáveis de metadados como região do país, estado e jornal. Em seguida, os textos foram coletados por dois pesquisadores e tabulados no Microsoft Word on-line.

As notícias foram organizadas em formato de corpus textual e analisadas com suporte do software Interface de R pourles Analyses Multidimensionnelles de Textes et de Questionnaires (Iramuteq), que viabiliza a execução de diversos tipos de análises de textos mediante a lexicografia básica (cálculo de frequência de palavras), a saber: pesquisa de especificidades de grupos, análise de similitude, estatística textual clássica, classificação hierárquica descendente (CHD) e nuvem de palavras ${ }^{15,16}$. Para o presente estudo, foi considerado pertinente a utilização da CHD, uma vez que esta permite a organização do conteúdo das notícias em classes constituídas pela aproximação léxica, sendo essas agrupadas por semelhança lexicográfica, o que conduz à formação dos subcorpora A e B a partir do próprio corpus textual ${ }^{16}$.

Após a análise léxica das palavras provenientes entre as classes da CHD e seus respectivos segmentos textuais, foi realizada análise de conteúdo proposta por Bardin $(2016)^{17}$, método que consiste em três etapas: pré-análise (eleição do material e determinação dos procedimentos a serem seguidos); exploração do material; e tratamento e interpretação dos dados ${ }^{17}$. Os resultados foram expostos por meio de dendrograma e quatro categorias temáticas. 
Com caráter documental, o presente estudo dispensa apreciação de Comitê de Ética e Pesquisa, amparado pela resolução 510 do Conselho Nacional de Saúde de $2016^{18}$.

\section{Resultados e discussão}

Apresenta-se descrição geral das análises realizadas pelo Iramuteq e nomeação das classes, considerando a frequência de aparecimento das palavras, as quais foram transformadas em categorias a partir da análise de conteúdo de Bardin $(2016)^{17}$.

A análise lexicográfica do corpus textual produto do conteúdo das 102 notícias on-line é detalhada a seguir: número de textos $=68$; ocorrências de palavras $=38681$; número de segmentos de texto $=1087$ (sendo 874 segmentos selecionados, o que representa um percentual de aproveitamento de 80,4\%); número de formas $=5824$; e hapax $=2056$ correspondendo a 5,32\%.

A CHD produziu quatro classes a partir do conteúdo analisado: classe 1, com 274 segmentos de texto ST (31,35\%); classe 2, com 231 ST (26,43\%); Classe 3, com 180 ST (20,59\%); e classe 4, com 189 ST (21,62\%), de acordo com dendrograma da figura 1.

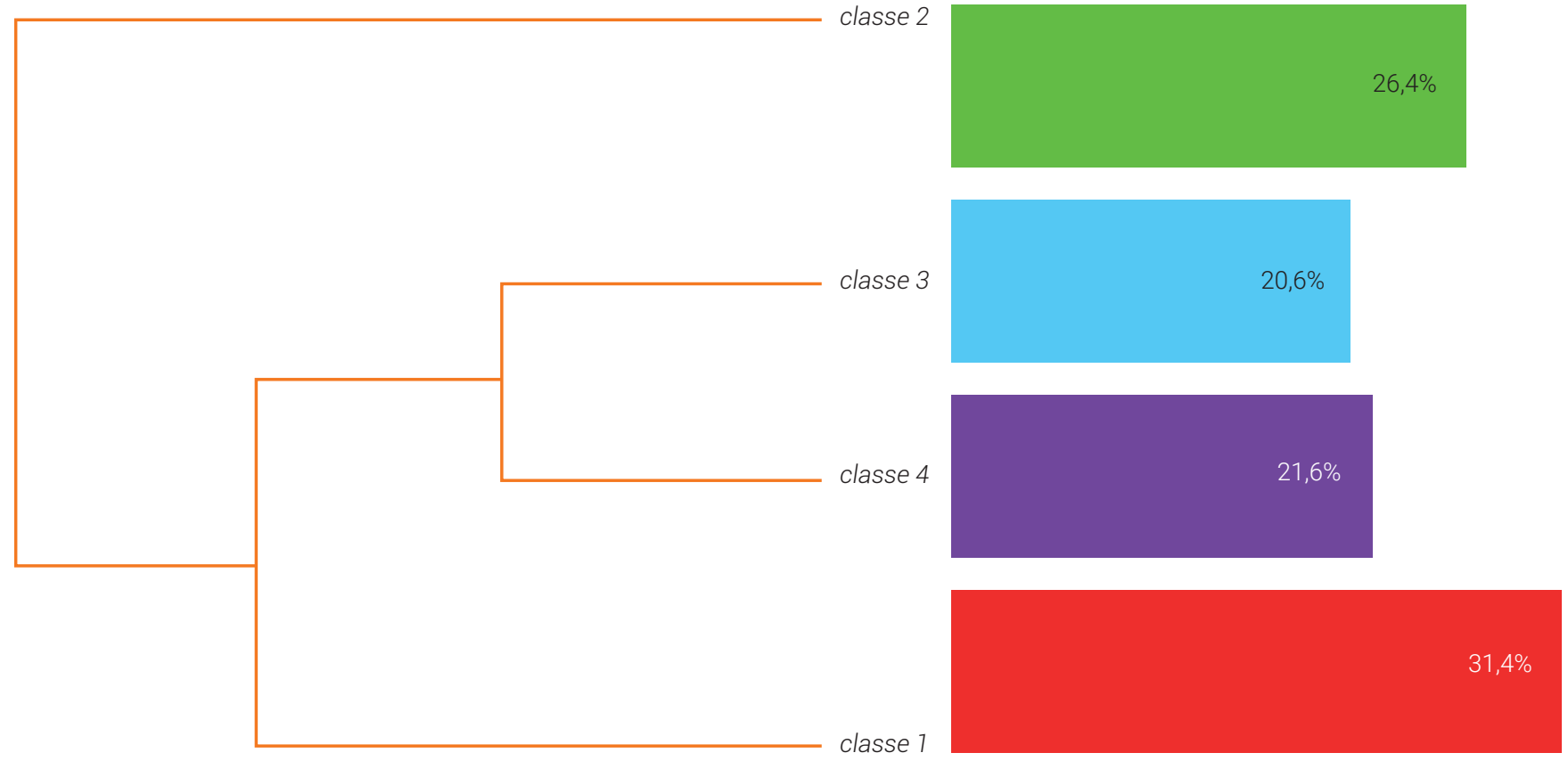

Subcorpus A - Aspectos de produção e combate à violência doméstica

Figura 1. Dendrograma da CDH do corpus textual referente ao conteúdo de notícias on-line sobre violência doméstica no período de isolamento social, Brasil, 2020 
As quatro classes geradas pela $\mathrm{CHD}$ se dividem em dois subcorpora, $\mathrm{A}$ e $\mathrm{B}$, que se subdividem em ramificações do corpus textual total. Para essas subdivisões, evidencia-se categorias temáticas extraídas da análise de conteúdo de Bardin (2016) ${ }^{17}$.

O subcorpus A foi denominado "Aspectos de produção e combate da violência doméstica", o qual se subdivide nas classes 1,3 e 4 . A classe 1 (Rede de proteção às vítimas de violência doméstica) tem como foco a rede de proteção à violência doméstica composta pelos órgãos jurídicos, sociais, governamentais e não governamentais que atuam nesse processo. A outra subdivisão do subcorpus A compóe-se por duas ramificaçóes, compreendendo as classes 3 e 4; a classe 4 ( $\mathrm{O}$ ambiente doméstico como espaço propulsor da violência doméstica) versa sobre o cenário familiar e doméstico como o espaço privilegiado de ocorrência das situaçóes de violência, sendo, assim, elemento de risco para as vítimas de violência; e a classe 3 (Contexto da pandemia como potencializador da violência doméstica) envolve os efeitos do distanciamento social na violação dos direitos da mulher, criança, adolescente e idosos, que são os grupos mais vulneráveis no contexto doméstico.

O subcorpus B, denominado "Violência doméstica e distanciamento social", é composto pela classe 2 (Elevação dos casos de violência doméstica em tempos de pandemia), que compreende a identificação, pelas autoridades governamentais e não governamentais, do aumento de casos de violência doméstica após o início do distanciamento social, e indica alertas sociais frente ao momento de distanciamento social.

$\mathrm{Na}$ figura 2, tem-se um diagrama com a lista de palavras para detalhar as classes evidenciadas; a composição de cada uma dessas classes foi definida a partir do teste qui-quadrado, tendo como ponto de corte de $\mathrm{x}^{2}>3,84$. O diagrama demonstra a presença de termos linguísticos semelhantes entre si em associação às classes que emergiram a partir da CHD. 


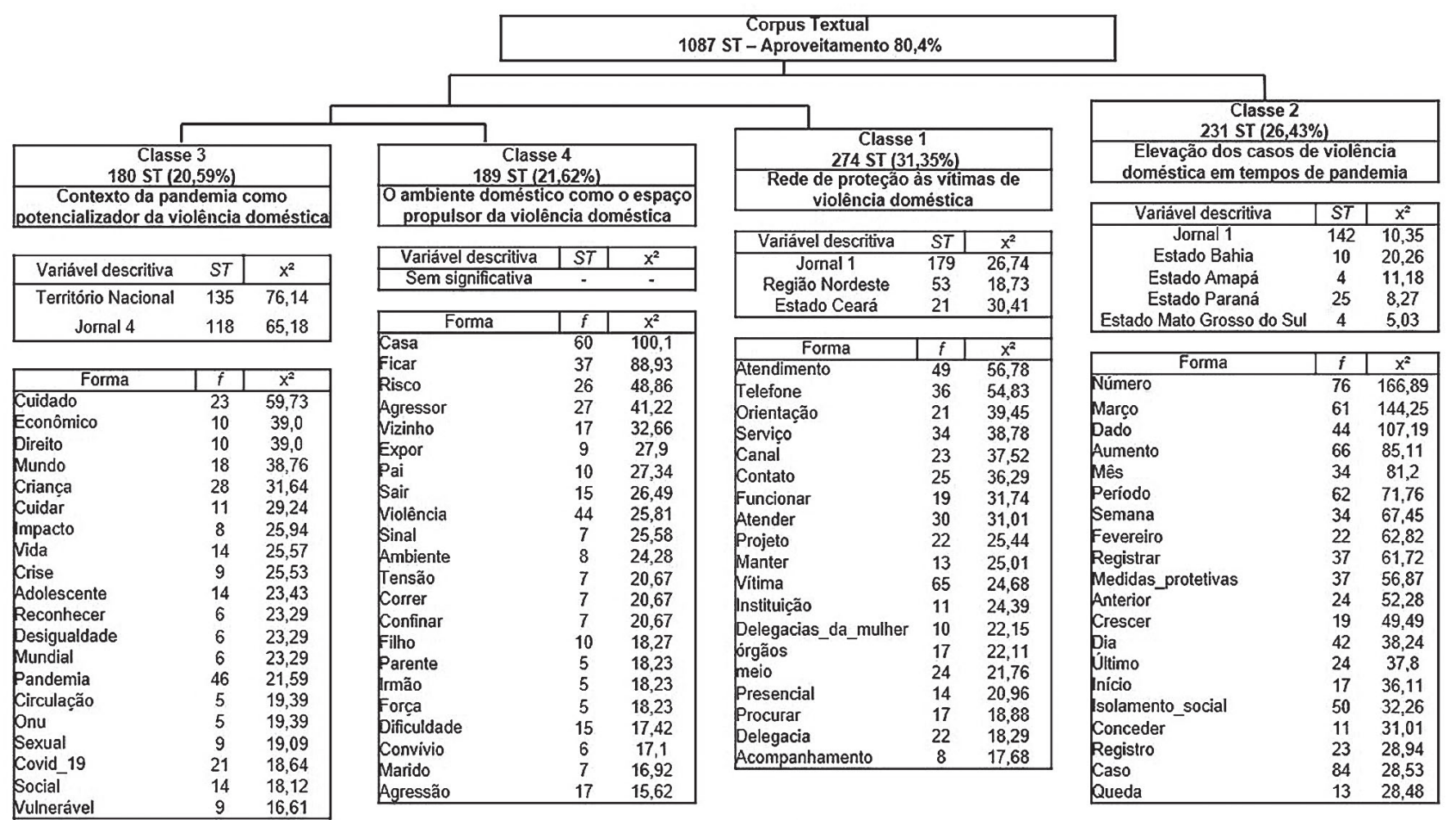

Legenda: ST - quantidade de segmentos de texto; $f-n^{\circ}$ de segmentos de texto que contem a palavra na classe; $x^{2}$ - qui-quadrado de associação da palavra com a classe

Figura 2. Diagrama das classes integrantes do dendrograma do corpus textual referente ao conteúdo de notícias on-line sobre violência doméstica no período de isolamento social, Brasil, 2020

\section{Aspectos de produção e combate à violência doméstica}

\section{Rede de proteção às vítimas de violência doméstica}

A rede de proteção emergiu da classe 1 , na qual predominaram as notícias do jornal $1\left(x^{2}=26,74\right)$, região Nordeste $\left(x^{2}=18,73\right)$ e o estado do Ceará $\left(x^{2}=30,41\right)$. O conteúdo relativo a essa categoria se refere aos mecanismos de proteção mobilizados para atuar junto às vítimas de violência doméstica.

Identificou-se a mobilização de órgãos governamentais como os tribunais de justiça; as delegacias da mulher; as polícias civil e militar; e órgãos de assistência social em diferentes municípios do país, articulando ações para garantir a proteção das vítimas em situação de violência doméstica por meio de veículos on-line e virtuais, seja por aplicativos de mensagens, programas para realização de boletins de ocorrência on-line ou escutas para assistência psicológica de forma virtual, assistência fundamental conforme as seguintes notícias:

A falta de atendimento presencial não impede que os centros de referência atuem durante o distanciamento. As vítimas podem entrar em contato através do telefone. Esse telefone servirá para atender pessoas que necessitarem de atendimento nesse momento de crise, principalmente as mulheres. (J1; N34) 
O aplicativo local está disponível para celulares com sistemas operacionais Android e IOS e tem diversos recursos, como a denúncia via telefone pelo 180, por formulário e e-mail. As informações são enviadas diretamente para o Ministério da Mulher, Família e Direitos Humanos, que fica encarregado de providenciar as investigações. (J1; N43)

O acesso a serviços legais e de segurança podem estar limitados em tempos de pandemia; assim, é imprescindível que os sistemas legais respondam de maneira eficiente às necessidades das pessoas que sofrem violência doméstica em circunstâncias de distanciamento social, sem redução do serviço de proteção às vítimas e consequente rapidez nas respostas necessárias ${ }^{19}$.

Pode-se caracterizar a rede de proteção governamental pelos seguintes serviços: Delegacias Especializadas de Atendimento a Mulher (DEAMs), Centros de Referência de Atendimento à Mulher, Casas-Abrigo, Casas de Acolhimento Provisório, Tribunal de Justiça, Defensorias da Mulher, Centros de Referência da Assistência Social (Cras), Conselhos Tutelar para a população infantojuvenil e idosos, Polícia Civil e Polícia Militar ${ }^{20-22}$.

As estratégias governamentais e não governamentais formuladas no Brasil basearam-se em ampliação de atendimentos telefônicos, espaços virtuais de apoio e implementação de meios digitais de denúncia com envio de fotos, vídeos ou depoimentos. Essa estratégia emergiu como uma possibilidade viável à situação emergencial, trazendo um aparato de possibilidades para as vítimas recorrerem aos serviços de proteção e terem acesso às principais medidas protetivas ${ }^{23}$. Açôes assim tornam-se alternativas para as vítimas de violência doméstica na busca pela garantia de seus direitos.

Constatou-se também que articulações não governamentais participam dessa rede de apoio, demonstrando mobilização para ampliá-la por meio da criação de aplicativos de denúncias e apoio às vítimas de violência doméstica; e criando canais virtuais de suporte e proteção, conforme trecho a seguir:

Após receber a denúncia da vítima por meio do aplicativo, as mulheres do grupo fazem a denúncia pelo telefone 180 e acionam o serviço social da região. [...] Elas ligam para o homem e falam, estamos sabendo que você bateu na sua mulher. Já alertamos a vizinhança e todo o bairro está de olho em vocês. Isso não resolve o problema, mas estamos tentando minimizar a situação nesse momento. (J1; N19)

Apesar da mobilização social por meio de grupos de mulheres não garantir a resolução da problemática da violência no ambiente doméstico, representa canais de articulação com a rede de proteção institucional, uma vez que, na maioria das situaçôes, a vítima sozinha não a produziria. Ademais, uma rede de proteção a vítimas se baseia em articulaçóes governamentais, não governamentais e da sociedade civil para identificação e proteção de pessoas em situação de vulnerabilidade e violência ${ }^{24}$. A vulnerabilidade das vítimas de violência doméstica é um ponto relevante em diversas situaçôes e ainda mais em realidades críticas como a atual. 
Os meios de denúncia são fatores importantes para o processo de garantia dos direitos e intervenção em situaçóes de violência. Ter locais passíveis de apoio integrado não só amplia as possibilidades de resolução diante da problemática da violência como também fortalece as vítimas que se sentem acolhidas e assistidas em seus direitos já preconizados por lei ${ }^{25}$.

Além disso, o espaço de escuta às vítimas de maneira virtual pode ser um importante aliado para fornecer um ambiente favorável e encorajador de denúncias para as vítimas que se encontram com limitaçóes no processo decisório de denunciar e quebrar o ciclo da violência a que estão submetidas. Tal realidade é influenciada pelo impacto negativo psicossocial da pandemia e seus prejuízos ${ }^{7}$, somada ao dano psicológico do risco e situaçốes de violência ${ }^{26}$; assim, torna-se ainda mais necessário a atuação profissional e comunitária em planos de ação com base na prevenção de agravos e incertezas das vítimas.

A ampliação das possibilidades de denúncia com meios digitais por parte das vítimas e da sociedade civil não é suficiente para o combate do problema em questão, principalmente no atual caos instalado, que pode dar a falsa impressão ao agressor e vítima de que não há soluçốes possíveis devido ao confinamento e restrição de serviços gerais ${ }^{11}$.É necessário que, além desses meios virtuais, exista um fortalecimento na prevenção dessas situaçóes; capacitação profissional para manejo e identificação da violência; divulgação das possibilidades de serviços; e acesso a meios de proteção (casas de apoio), independentemente da situação de distanciamento.

\section{Contexto da pandemia como potencializador da violência doméstica}

Essa categoria faz referência à classe 3 , para a qual predominou as notícias relativas ao jornal $4\left(x^{2}=65,18\right)$ e a todo o território nacional $\left(x^{2}=76,14\right)$, ou seja, notícias nacionais. O conteúdo dessa categoria destaca os impactos sociais e econômicos produzidos pela pandemia de Covid-19, construindo um cenário de crise na sociedade brasileira e mundial e, entre os problemas sociais agravados pelo período pandêmico, tem-se a violência doméstica.

A crise social, sanitária e econômica trazida pela pandemia de Covid-19 impacta diretamente na vulnerabilidade social de diversos grupos já anteriormente vulneráveis e exacerbam as desigualdades sociais. Sujeitos como mulheres, crianças em condição de exploração, negros, refugiados e imigrantes representam grupos de pessoas que podem ser mais afetados, uma vez que o impacto dessa crise mundial perpassa a esfera individual, atingindo também as esferas relacional, comunitária e social ${ }^{12}$.

Essa preocupação com a vulnerabilidade social dos grupos com maior risco de perda de direitos pode ser percebida nos trechos das notícias elencadas, tais como a seguinte:

A vulnerabilidade das famílias tem sido uma preocupação para diversas entidades de defesa dos direitos de crianças e adolescentes. Isso não significa que as entidades sejam contra o distanciamento, mas sim a favor de medidas protetivas para as pessoas em maior vulnerabilidade durante este período. (J4; N50) 
Constatar a existência de desigualdades sociais e maior vulnerabilidade para determinados grupos se faz essencial para compreender como os problemas trazidos pela Covid-19 representam a intensificação de fragilidades, que já assolavam a sociedade brasileira, como a desigualdade de gênero, o comportamento machista, as relaçóes de poder abusivas e a exclusão das minorias ${ }^{11}$.

Nesse sentido, o distanciamento social não deve ser considerado como um produtor da violência doméstica, porém, um potencializador de situaçôes de violência que já existiam nos ambientes domésticos. Tais aspectos têm sido ressaltados por relatórios internacionais, a exemplo do citado na notícia a seguir, que foca a violência direcionada à mulher:

Uma em cada três mulheres em todo o mundo já sofreu violência física e/ou sexual, mas é provável que esta crise piore como resultado da pandemia do novo coronavírus, aponta o relatório. À sombra da pandemia, violência contra mulheres e meninas e Covid-19. O documento foi divulgado em abril pela Organização das Naçốes Unidas Mulheres, entidade da Organização das Nações Unidas para igualdade de gênero e empoderamento. (J4; N9)

O distanciamento social imposto pela pandemia da Covid-19 traz à tona, de forma potencializada, indicadores preocupantes acerca da violência doméstica ${ }^{11}$. Não se trata de um novo objeto de estudo, mas de algo com raízes histórico-culturais permeadas por crenças, tradições e valores, que fundamentam a interpretação do fenômeno, inclusive na área da Saúde?.

Indicadores sociais como desemprego, pobreza e diminuição da perspectiva de melhora da situação financeira, aspectos agravados pelo período de crise pandêmica, podem interferir no relacionamento interpessoal familiar e consequentemente dificultar o manejo de problemas cotidianos, sendo estopim para situaçóes de agressão doméstica ${ }^{27}$, tal como destaca o texto da notícia a seguir: "A entidade avalia que o impacto econômico da pandemia pode criar barreiras adicionais para deixar um parceiro violento. Em um contexto de emergência, aumentam os riscos de violência" (J4; N63).

A probabilidade de que mulheres, crianças, idosos e outros grupos vulneráveis sejam expostos à violência aumenta drasticamente à medida que os membros da família passam mais tempo juntos, bem como enfrentam estresses adicionais e potenciais perdas econômicas ou de emprego, que estão associadas à realidade atual ${ }^{28}$.

Aprofundar discussóes acerca do impacto do contexto aversivo que envolve ambiência desfavorável e risco de violência se torna imprescindível para nortear açóes governamentais para intervenção nesse fenômeno ${ }^{29}$. Percebe-se uma preocupação mundial com a violação de direitos humanos em época da pandemia:

[...] desde o dia 18 de março já recebeu 6.772 denúncias de violaçóes de direitos humanos, das quais as principais vítimas são crianças, idosos, mulheres e pessoas com deficiência. Essas e outras questóes de direitos infantojuvenis geraram pronunciamentos públicos de representantes da Organização das Naçóes Unidas e do Fundo das Naçôes Unidas para a Infância com relação ao cenário mundial. (J4; N4) 
O enfrentamento dessa forma de violência, especialmente no cenário atual, demanda ações mais efetivas e que incluam diferentes setores da sociedade ${ }^{30}$, uma vez que precisam ser assistidas em suas vulnerabilidades, encontrando segurança, proteção e resolutividade nos serviços sociais e de saúde ${ }^{31}$.

A invisibilidade e a impunidade de grande parte dos casos de violência doméstica contribuem para sua marginalização e a mínima busca de auxílio por suas vítimas, contribuindo para a perpetuação do ciclo $^{13}$. Esse fenômeno não pode ser analisado fora de um contexto social e cultural vigente, sendo, assim, fundamental a criação de dispositivos sociais, institucionais e jurídicos para o enfrentamento dessas questóes ${ }^{32}$.

\section{0 ambiente doméstico como o espaço propulsor da violência doméstica}

Essa terceira categoria remete-se à classe 4, na qual não se associou nenhuma variável em específico, o que demonstra semelhança no conteúdo das notícias distribuídas nacionalmente, sem destacar para alguma região ou estado do país.

O conteúdo linguístico que compôs essa categoria ressalta o ambiente doméstico em um momento de distanciamento social como o espaço estimulador da violência doméstica.

A permanência obrigatória no ambiente doméstico expóe ao contato direto entre vítima e agressor, associada a questôes nas relaçôes familiares, desigualdade sociais, de poder e de gênero que favorecem a hostilidade dentro do lar, além da ineficiência de medidas adequadas no combate a Covid-19. Observa-se também entraves que favoreceram a ocorrência da violência doméstica, como a cultura de violência, manejo ineficaz do Estado e diminuição do acesso a serviços assistenciais e de proteção à vítima ${ }^{11}$.

O aumento da exposição cotidiana de grupos vulneráveis como mulheres e crianças nas instalações comuns dos agressores tem tido maior evidência no momento de distanciamento social ocasionado pela pandemia de Covid-19. Cenários de crises confirmam que a proximidade domiciliar por longos períodos expóe a diminuição de liberdade e privacidade e o aumento de estresse físico e psicológico ${ }^{19}$.

O distanciamento social com peculiaridades de encarceramento, compreendido como a restrição no microssistema doméstico e a limitação a outros microssistemas habituais, com consequente fragilização do acesso ao mesossistema no qual se encontram as redes de apoio e proteção ${ }^{33}$, potencializa a permanência da vítima no ciclo de violência doméstica, uma vez que esta vivencia a falta de convívio social; desse modo, as relaçốes de apoio são fragilizadas pela distância e a impossibilidade de recorrer a membros da família e rede de apoio fora do ambiente de agressão, como enfatizam as seguintes notícias:

As mulheres também ficam privadas de muitas das suas estratégias diárias para fugir da relação abusiva, como o ambiente de trabalho e as redes de amigos e familiares. Presa em casa, suas possibilidades de socorro ficam limitadas. (J4; N61) 
Nesse momento, as mulheres que já sofrem com relacionamentos abusivos correm mais perigo porque não estão conseguindo escapar do agressor. O fato dessas mulheres estarem dentro de casa com seus agressores, muitas vezes sem se deslocar para ir ao trabalho, faz com que elas denunciem menos. (J1; N81)

O contexto persistente de distanciamento furta consideravelmente as alternativas de relaçôes de cuidado e proteção entre a vítima e uma possível rede de apoio, constituindo-se em um obstáculo para proteção de direitos e fator de aumento da vulnerabilidade ${ }^{25}$.

A existência de uma rede familiar e extrafamiliar de apoio e proteção influencia decisivamente na manutenção ou na quebra dos ciclos de violência doméstica, uma vez que a vítima necessita de elementos externos em que possa se apoiar, conduzir a situação de violência doméstica ou até executar a remoção da vítima do ambiente doméstico agressor ${ }^{34}$.

Ressalta-se a relevância da intervenção social nessa realidade por parte dos vizinhos, que podem identificar e denunciar situações de violência doméstica, conforme explicitado nos trechos das seguintes notícias:

Por isso é muito importante a participação da população nessa situação, para ficar atento, se houver algum pedido de socorro, preste ajuda, principalmente se sabemos que aquela pessoa sofre violência e está na presença do agressor em casa, alerta a delegada. (J1; N43)

Então, é preciso que essa mulher chame, peça ajuda, peça ajuda a um vizinho, a uma irmã, grite, ligue, porque essa é uma forma também de intimidar o agressor. $(\mathrm{J} 1 ; \mathrm{N} 71)$

O apoio social no sentido de fortalecer e preparar as vítimas para enfrentar a realidade da violência doméstica pode ser visualizada entre os vizinhos, que são peçaschave para a denúncia no momento das agressóes. A vizinhança pode representar abrigo para compartilhamento de emoçôes e sentimentos, assim como suporte de recursos materiais, essenciais em situaçóes de crise ${ }^{35}$.

É fundamental pontuar o apoio da sociedade na produção das denúncias frente às situaçôes de violência doméstica presenciadas nas comunidades, especialmente neste período de distanciamento social, por meio do acionamento da rede de proteção jurídica, policial e de assistência social para intervir nos casos.

O ambiente doméstico não abriga somente a violência doméstica com mulheres: crianças, adolescentes, idosos, população LGBT, pessoas com deficiências, população negra e outras minorias se encontram também como grupos ainda mais vulneráveis à violência nesse período de distanciamento social, sobretudo quando mais de uma dessas características coexistem. Destaca-se que esses grupos apresentam uma fragilidade maior para solicitar ajuda aos órgãos de proteção pelas próprias condiçôes de desenvolvimento, senilidade e fatores sociais e culturais intrínsecos, o que mantém essas vítimas na invisibilidade. 
O aparente silenciamento das situaçóes de violência doméstica com esses grupos populacionais, neste momento de pandemia, pode ser visualizado nas notícias que compóem este estudo, que demonstram um foco evidente nas situaçốes de violência contra a mulher.

\section{Violência doméstica e o distanciamento social}

\section{Elevação dos casos de violência doméstica em tempos de pandemia}

A quarta categoria se refere à classe 2 , na qual predominaram as notícias do jornal $1\left(x^{2}=10,35\right)$ e dos estados da Bahia $\left(x^{2}=20,26\right)$, Amapá $\left(x^{2}=11,18\right)$, Paraná $\left(x^{2}=8,27\right)$ e Mato Grosso do Sul $\left(x^{2}=5,03\right)$. O conteúdo relativo a essa categoria se refere aos dados de elevação das situaçôes de violência doméstica após o início do distanciamento social no Brasil; apesar da análise dos dados evidenciar quatro estados em específicos, identificou-se essa elevação em diversas cidades brasileiras.

A elevação do número de casos de violência doméstica foi produto da comparação realizada pelos jornais com meses anteriores ou ao mesmo com o mesmo mês do ano anterior. Outro elemento importante considerado nas avaliaçốes baseou-se no quantitativo das medidas protetivas que se mantiveram ou aumentaram concomitantemente aos casos de violência doméstica. As notícias que fizeram referências a esse aumento da violência doméstica utilizaram dados oficiais das delegacias da mulher e dos tribunais de justiça.

Além das mortes, a Secretaria Estadual de Segurança Pública também divulgou um aumento no número de boletins de ocorrência na Delegacia da Mulher. Foram registradas 385 denúncias de violência doméstica no último mês de março, 31 a mais do que o registrado em fevereiro de 2020. (J4; N9)

Número de denúncias de violência contra a mulher aumenta mais de 100 por cento no distanciamento social. Dados foram registrados por aplicativo [...]. Maior aumento registrado entre o mês anterior e o mês de distanciamento social ocorreu em casos de violência moral. (J1; N43)

Os dados brasileiros divulgados pelo Ministério da Mulher, da Família e dos Direitos Humanos em site governamental, relativos às denúncias de violência contra a mulher recebidas por telefone, indicam que o país segue a tendência mundial de aumento dos casos de violência doméstica em meio ao período de distanciamento e destacam a importância e urgência de criação de estratégias para minimizar esse movimento crescente ${ }^{36}$.

Corroborando, pesquisadores ${ }^{37}$ chamam a atenção quanto ao aumento significativo de casos de violência doméstica em países em situações de pandemia, como China, Espanha, Itália e Brasil, sendo que este último se destaca com uma estimativa de aumento de 50\% 
das denúncias. Nesse cenário, o enfrentamento da violência implica na desconstrução de normas sociais e padróes culturais, tanto de homens quanto de mulheres, os quais confirmam, autorizam, naturalizam e banalizam a dominação masculina sobre a mulher ${ }^{38}$.

Em contrapartida, algumas notícias referiram redução do número de denúncias, pedidos de ajuda e medidas protetivas para situaçôes de violência doméstica. Nesse cenário, avalia-se que a queda no número de chamados nos veículos oficiais não representa a redução da violência doméstica, mas indica alerta para a limitação de procura por ajuda ocasionada pela presença constante do agressor:

Fórum Brasileiro de Segurança Pública aponta que queda não significa redução nos casos, mas, sim, dificuldade de acesso ao atendimento. $\mathrm{O}$ número de pedidos de medidas protetivas para mulheres que sofrem violência doméstica diminuiu 38 por cento nas duas primeiras semanas de abril em relação aos números do mês de março. (J4; N9)

Essa aparente contradição na notificação de casos também foi observada na Espanha $^{39}$, lembrando que essa diminuição não indica redução do número de casos, mas sim evidencia maior dificuldade de acesso aos serviços de apoio. Apesar de o estudo discutir especificamente a violência de gênero, as razóes trazidas pelos autores podem justificar essa redução no número de denúncias também elencadas no Brasil.

A subnotificação de casos de violência contra idosos, crianças e adolescentes sempre foi um problema de saúde pública observado no Brasil antes da pandemia de Covid-19. Apesar de, momentaneamente, o noticiamento e indicadores apresentarem-se em menor número nesses grupos vulneráveis, os trechos indicam aumento dos casos de violência doméstica nos grupos supracitados (idosos, crianças e adolescentes):

Número de idosos vítimas de violência ou abandono aumenta durante a pandemia em Petrolina. Um levantamento realizado pela prefeitura da cidade apontou o aumento de denúncias em mais de 100 por cento desde o mês de fevereiro, sendo o mês de março com maior pico de registros. (J1; N78)

[...] promotor alerta para aumento de casos de abusos sexuais de crianças e adolescentes no período de pandemia do coronavírus. [...] crimes cibernéticos de exploração sexual registraram aumento em locais onde a Covid-19 ocorre há mais tempo. $(\mathrm{J} 1 ; \mathrm{N} 92)$

O processo de envelhecimento populacional gerou uma predominância de idosos no Brasil observada na curva demográfica; e a maioria deles está em estado de dependência psicológica ou financeira de outros, com diminuição na capacidade funcional e cognitiva; e presença de comorbidades e fragilidades nas relaçóes familiares e de cuidado, fato que aumenta o risco e os atos de violência direcionados à pessoa idosa ${ }^{40}$. 
Para crianças e adolescentes, o distanciamento pode levar à maior irritabilidade e agressividade relacionada às restriçóes que o contexto lhes imputa. Além disso, a interrupção das atividades escolares modificou a dinâmica das relaçôes domiciliares, amplificando as demandas dos pais e apresentando-se como propulsores para o desenvolvimento de conflitos ${ }^{12}$.

Em síntese, é relevante destacar que a violência doméstica encontra-se imbricada no contexto sociocultural e político das naçóes e povos, refletindo, inevitavelmente, no nível de intervenção governamental na defesa dos direitos humanos e na proteção dos grupos vulneráveis ${ }^{41}$, que se faz ainda mais necessária em contextos de crise como pandemia de Covid-19.

\section{Considerações finais}

Evidencia-se, a partir da análise crítica do conteúdo jornalístico, o agravamento da violência doméstica, de maneira alarmante, na conjuntura de distanciamento social e reclusão de vítimas no âmbito doméstico.

As redes de proteção às vítimas de violência doméstica buscaram alternativas on-line para permanecer atuando e garantindo o acesso e a manutenção de direitos no período emergencial, embora ainda seja necessário o fortalecimento dos meios de proteção e conscientização da sociedade para enfrentamento efetivo.

A pandemia e seus rebatimentos sociais, psicológicos, físicos, econômicos e estruturais revelaram-se como potencializadores da violência doméstica, sobretudo em grupos vulneráveis. Esse quadro exacerba uma realidade preexistente de vulnerabilidade e denuncia a necessidade de revisão articulada de estratégias de combate.

O espaço doméstico como local de distanciamento social para o enfrentamento da transmissão de Covid-19 tornou-se ambiente propulsor da violência doméstica, pois a restrição ao domicílio submeteu as vítimas ao constante contato com o agressor e limitou a busca por ajuda. A fragilidade de acesso à rede de proteção e suporte social intensifica a exposição das vítimas e minorias às situações de violência, e é neste contexto que o apoio social deve exercer papel ativo e mediador de quebra do ciclo violento com identificação e denúncias.

Embora haja aparente divergência entre as publicações jornalísticas quanto à elevação ou diminuição dessas denúncias, não se descarta que esses números divulgados podem refletir uma subnotificação já existente e possivelmente agravada.

Nessa conjuntura, açôes de intervençôes específicas para a realidade atual se tornam fundamentais para minimizar a ocorrência de violência doméstica e reduzir os danos decorrente dessas situaçóes de agressão. Destacam-se alguns indicativos de enfrentamento à violência de atuação imediata e eficaz:

a) Ampliação dos mecanismos de pedidos de proteção e denúncias nos órgãos governamentais por meio de aplicativos ou dispositivos que não dependam de internet, haja vista a vulnerabilidade social da população brasileira. 
(2)

b) Divulgação ampla desses mecanismos, para que toda a sociedade conheça os meios de alcance à rede de proteção.

c) Fortalecimento de instituições jurídicas e policiais envolvidas na proteção rápida e eficientes das vítimas em situações emergenciais.

d) engajamento dos profissionais de Saúde nos diversos serviços de saúde e nos três níveis de atenção à saúde no âmbito do Sistema Único de Saúde na identificação e no acolhimento de situações de violência doméstica.

e) participação da sociedade como rede de apoio às vítimas de violência doméstica que se encontram próximas, na mesma rua, nos condomínios e nos prédios.

O cenário atual exposto não pode ser minimizado ou posto na invisibilidade, uma vez que a maior parte das situações de violência doméstica já se encontra invisível. A elevação do número de casos alerta para inúmeras situaçóes de violência que permanecerão imperceptíveis; desse modo, uma atuação intersetorial deve priorizar o acolhimento e redução de danos dessas vítimas.

\section{Autores}

Francisco Arnoldo Nunes de Miranda ${ }^{(\mathrm{f})}$

$<$ farnoldo@gmail.com>

Rafaella Queiroga Souto(g)

<rqs@academico.ufpb.br>

\section{Contribuição dos autores}

Todos os autores participaram ativamente de todas as etapas de elaboração do manuscrito.

\section{Conflito de interesse}

Os autores não têm conflito de interesse a declarar.

\section{Direitos autorais}

Este artigo está licenciado sob a Licença Internacional Creative Commons 4.0, tipo BY (https://creativecommons.org/licenses/by/4.0/deed.pt_BR).

\section{(cc) BY}

\section{Editora}

Ana Flávia d’Oliveira

Editora associada

Maria Alice Garcia

\section{Submetido em}

$01 / 06 / 20$

Aprovado em

$14 / 01 / 20$ 


\section{Referências}

1. Batista JMS, Trigueiro TH, Lenardt MH, Mazza VA, Labronici LM. O modelo bioecológico: desvendando contribuiçóes para a práxis da enfermagem diante da violência doméstica. Esc Anna Nery. 2013; 17(1):173-8. Doi: 10.1590/S1414-81452013000100024.

2. Fiorati RC, Arcêncio RA, Souza LB. Social inequalities and access to health: challenges for society and the nursing field. Rev Lat Am Enfermagem. 2016; 24:e2687. Doi: $10.1590 / 1518-8345.0945 .2687$.

3. WHO Global consultation on violence and health. Violence: a public health priority. Geneva: WHO; 1996.

4. Miura PO, Silva ACS, Pedrosa MMMP, Costa ML, Nobre Filho JN. Violência doméstica ou violência intrafamiliar: análise dos termos. Psicol Soc. 2018; 30:e179670. Doi:10.1590/1807-0310/2018v30179670.

5. Lima GQ, Werlang BSG. Mulheres que sofrem violência doméstica: contribuiçóes da psicanálise. Psicol Estud. 2011; 16(4):511-20. Doi: 10.1590/S141373722011000400002 .

6. Arboit J, Costa MC, Silva EB, Colomé ICS, Prestes M. Violência doméstica contra mulheres rurais: práticas de cuidado desenvolvidas por agentes comunitários de saúde. Saude Soc. 2018; 27(2):506-17. Doi: 10.1590/s0104-12902018169293.

7. Fiorillo A, Gorwood P. The consequences of the COVID-19 pandemic on mental health and implications for clinical practice. Eur Psychiatry. 2020; 63(1):1-4. Doi: 10.1192 /j.eurpsy.2020.35.

8. Duan L, Zhu G. Psychological interventions for people affected by the COVID-19 epidemic. Lancet Psychiatry. 2020; 7(4):300-3. Doi: 10.1016/S2215-0366(20)30073-0.

9. Acosta DF, Gomes VLO, Oliveira DC, Marques SC, Fonseca AD. Representaçóes sociais de enfermeiras acerca da violência doméstica contra a mulher: estudo com abordagem estrutural. Rev Gauch Enferm. 2018; 39:e61308. Doi: 10.1590/1983-1447.2018.61308.

10. Garcia LP, Duarte E. Intervenções não farmacológicas para o enfrentamento à epidemia da COVID-19 no Brasil. Epidemiol Serv Saude. 2020; 29(2):e2020222. Doi: 10.5123/S1679-49742020000200009.

11. Vieira PR, Garcia LP, Maciel ELN. Isolamento social e o aumento da violência doméstica: o que isso nos revela? Rev Bras Epidemiol. 2020; 23(e200033):1-5. Doi: 10.1590/1980-549720200033.

12. Marques ES, Moraes CL, Hasselmann MH, Deslandes SF, Reichenheim ME. A violência contra mulheres, crianças e adolescentes em tempos de pandemia pela COVID-19: panorama, motivaçốes e formas de enfrentamento. Cad Saude Publica. 2020; 36(4):e00074420. Doi:10.1590/0102-311x00074420.

13. Santos WJ, Oliveira PPO, Viegas SMFV, Ramos TM, Policarpo AG, Silveira EAA. Violência doméstica contra a mulher perpetrada por parceiro íntimo: representações sociais de profissionais da Atenção Primária à Saúde. Rev Pesqui (Univ Fed Estado Rio J, Online). 2018; 10(3):770-7. Doi: 10.5205/1981-8963-v10i10a11439p3743-3750-2016.

14. Brasil. Ministério da Saúde. Secretaria de Vigilância em Saúde. Boletim Epidemiológico 07 [Internet]. Brasília: Ministério da Saúde; 2020 [citado 20 Maio 2020]. (Semana Epidemiológica 15). Disponível em: http://www.cofen.gov.br/wpcontent/uploads/2020/04/Boletim-07-MS-06-04-2020.pdf.pdf 
15. Kami MTM, Larocca LM, Chaves MMN, Lowen IMV, Souza VMP, Goto DYN. Trabalho no consultório na rua: uso do software IRAMUTEQ no apoio à pesquisa qualitativa. Esc Anna Nery. 2016; 20(3):e20160069. Doi: 10.5935/1414-8145.20160069.

16. Camargo BV, Justo AM. IRAMUTEQ: um software gratuito para análise de dados textuais. Temas Psicol. 2013; 21(2):513-8.

17. Bardin L. Análise de conteúdo. Pinheiro LA, tradutor. São Paulo: Edições 70; 2016.

18. Brasil. Ministério da Saúde. Resolução no 510, de 7 de Abril de 2016. Trata das especificidades éticas das pesquisas nas ciências humanas e sociais. Brasília: Ministério da Saúde; 2016.

19. Peterman A, Potts A, O’Donnell M, Thompson K, Shah N, Oertelt-Prigione S, et al. Pandemics and violence against women and children [Internet]. Washington: Center for Global Development; 2020 [citado 12 Maio 2020]. Disponível em: https://www. cgdev.org/publication/pandemics-and-violence-against-women-and-children

20. Faraj SP, Siqueira AC, Arpini DM. Rede de proteção: o olhar de profissionais do sistema de garantia de direitos. Temas Psicol. 2016; 24(2):727-41. Doi: 10.9788/TP2016.2-18.

21. Albuquerque Netto L, Moura MAVM, Araújo CLF, Souza MHNS, Silva GF. As redes sociais de apoio às mulheres em situação de violência por parceiro íntimo. 2017; 26(2):e07120015. Doi: 10.1590/0104-07072017007120015.

22. Borburema TLR, Pacheco AP, Nunes AA, Moré CLOO, Krenkel S. Violência contra mulher em contexto de vulnerabilidade social na Atenção Primária: registro de violência em prontuários. Rev Bras Med Fam Comunidade. 2017; 12(39):1-13. Doi: $10.5712 / \mathrm{rbmfc} 12(39) 1460$.

23. Brasil. Ministério da Mulher, Família e Direitos Humanos. Mulheres na COVID-19 [Internet]. Brasília: Ministério da Mulher, Família e Direitos Humanos; 2020 [citado 12 Maio 2020]. Disponível em: https://www.gov.br/mdh/pt-br/assuntos/ noticias/2020-2/abril/cartilha-orienta-mulheres-durante-a-pandemia-do-coronavirus/ mulherescovid19_Alterado_corrigido.pdf

24. Pasinato W. Oito anos de Lei Maria da Penha: entre avanços, obstáculos e desafios. Estud Fem. 2015; 23(2):533-45. Doi: 10.1590/0104-026X2015v23n2p533.

25. Machado DF, Almeida MAS, Dias A, Bernardes JM, Castanheira ERL. Violência contra a mulher: o que acontece quando a Delegacia de Defesa da Mulher está fechada? Cienc Saude Colet. 2020; 25(2):483-94. Doi: 10.1590/1413-81232020252.14092018.

26. Llosa MS, Canetti WA. Depresión e ideación suicida en mujeres víctimas de violencia de pareja. Psicol Conoc Soc. 2019; 9(1):138-60. Doi: 10.26864/pcs.v9.n1.1.

27. Honnef F, Costa MC, Arboit J, Silva EB, Marques KA. Representaçốes sociais da violência doméstica em cenários rurais para mulheres e homens. Acta Paul Enferm. 2017; 30(4):368-74. Doi: 10.1590/1982-0194201700054.

28. Organização Pan-American da Saúde. Folha informativa - COVID-19 [Internet]. Washington: OPAS; 2020 [citado 15 Maio 2020]. Disponível em: https://www. paho.org/pt/covid19

29. Lucena KDT, Vianna RPT, Nascimento JA, Campos HFC, Oliveira ECT. Association between domestic violence and women's quality of life. Rev Lat Am Enfermagem. 2017; 25:e2901. Doi: 10.1590/1518-8345.1535.2901.

30. Delziovo CR, Bolsoni CC, Nazário NO, Coelho EBS. Características dos casos de violência sexual contra mulheres adolescentes e adultas notificados pelos serviços públicos de saúde de Santa Catarina, Brasil. Cad Saude Publica. 2017; 33(6):1-13. Doi: 10.1590/0102-311x00002716. 
31. Sehnem GD, Lopes EB, Tier CG, Ribeiro AC, Maciel VQS, Castilhos L. Violência contra as mulheres: atuação da enfermeira na atenção primária à saúde. Rev Enferm UFSM. 2019; 9(e62). Doi: 10.5902/2179769235061.

32. Brooks SK, Webster RK, Smith LE, Woodland L, Wessely S, Greenberg N, Rubin GJ. The psychological impact of quarantine and how to reduce it: rapid review of the evidence. Lancet. 2020; 395(10227):912-20. Doi: 10.1016/S0140- 6736(20)30460-8.

33. Rocha RZ, Galeli PR, Antoni CD. Rede de apoio social e afetiva de mulheres que vivenciaram violência conjugal. Contextos Clin. 2019; 12(1):124-52. Doi: 10.4013/ ctc. 2019.121 .06

34. Ribeiro LMA, Leite LMC. Violência doméstica, infância e rede de apoio. Rev Latinoam Psicopatol Fundam. 2018; 21(3):646-59. Doi: 10.1590/1415-4714.2018v21n3p646.12.

35. Souza MB, Silva MFS. Estratégias de enfrentamento de mulheres vítimas de violência doméstica: uma revisão da literatura brasileira. Pensando Fam. 2019; 23(1):153-66.

36. Brasil. Ministério da Mulher, da Família e dos Direitos Humanos. Coronavírus: sobe o número de ligaçôes para canal de denúncia de violência doméstica na quarentena [Internet]. Brasília: ODNH, MMFDH; 2020 [citado 28 Maio 2020]. Disponível em: https://www.gov.br/mdh/pt-br/assuntos/noticias/2020-2/marco/coronavirus-sobe-onumero-de-ligacoes-para-canal-de-denuncia-de-violencia-domestica-na-quarentena

37. World Health Organization. COVID-19 and violence against women what the health sector/system can do [Internet]. Genebra: WHO; 2020 [citado 12 Maio 2020]. Disponível em: https://www.who.int/reproductivehealth/publications/vaw-covid-19/en/

38. Gontijo DT, Alves HC, Paiva MHP, Guerra RMR, Kappel VB. Violência e saúde: uma análise da produção científica publicada em periódicos nacionais entre 2003 e 2007. Physis. 2010; 20(3):1017-54. Doi: 10.1590/S0103-73312010000300017.

39. Ruiz-Pérez I, Pastor-Moreno G. Medidas de contención de la violencia de género durante la pandemia de COVID-19. Gac Sanit (Barcelona). 2020:1-6. Doi: 10.1016/j. gaceta.2020.04.005.

40. Maia PHS, Ferreira EF, Melo EM, Vargas AMD. A ocorrência da violência em idosos e seus fatores associados. Rev Bras Enferm [Internet]. 2019 [citado 28 Maio 2020]; 72 Suppl 2:64-70. Doi: 10.1590/0034-7167-2018-0014.

41. Oliveira MHB, Viana MB, Schütz GE, Teles N, Ferreira AP. Direitos humanos, justiça e saúde: reflexóes e possibilidades. Saude Debate. 2019; 43(spe 4):9-14. doi:10.1590/0103-11042019S401. 
This study analyzed the effects of social distancing in times of Covid-19 on domestic violence. We conducted a documentary study of news content in four online national newspapers. The study included news published between 20 March and 25 April 2020 addressing social distancing and domestic violence. A content analysis was conducted using the software IRAMUTEQ adopting the approach proposed by Bardin. The lexicographic and content analysis of the corpus of 102 news items produced four thematic categories: protection networks, the home environment, the increase in cases of domestic violence, and the pandemic as a driver of the phenomenon. Social distancing imposed during the Covid-19 pandemic exacerbated domestic violence, demonstrating the need for interventions and the strengthening of the protection network.

Keywords: Domestic violence. Violence. Coronavirus. Pandemic. Social distancing.

Analizar las implicaciones del distanciamiento social en tiempos de Covid-19 alrededor de la violencia doméstica. Estudio documental con abordaje cualitativo, por medio del contenido de noticias disponibles en cuatro periódicos online de circulación nacional. Se incluyeron noticias publicadas entre el 20 de marzo y el 25 de abril de 2020 con estas temáticas: distanciamiento social y violencia doméstica, analizadas por el software IRAMUTEQ, asociado al análisis de contenido de Bardin. El análisis lexicográfico y de contenido del corpus textual de 102 noticas produjo cuatro categorías temáticas enfocadas en la red de protección, ambiente doméstico, elevación de los casos de violencia doméstica y el contexto de pandemia como potenciador del fenómeno. El distanciamiento social proveniente de la pandemia de Covid-19 potenció las situaciones de violencia doméstica, demostrando la necesidad de medidas de intervenciones y fortalecimiento de la red de protección.

Palabras clave: Violencia doméstica. Violencia. Coronavirus. Pandemia. Distanciamiento social. 